\title{
An empirical model of ionospheric total electron content (TEC) near the crest of the equatorial ionization anomaly (EIA)
}

\author{
Rajkumar Hajra ${ }^{1,2, a,{ }^{*}}$, Shyamal Kumar Chakraborty ${ }^{3}$, Bruce T. Tsurutani ${ }^{4}$, Ashish DasGupta ${ }^{5}$, Ezequiel Echer ${ }^{1}$, \\ Christiano G.M. Brum ${ }^{2}$, Walter D. Gonzalez ${ }^{1}$, and José Humberto Andrade Sobral ${ }^{1}$ \\ 1 Instituto Nacional de Pesquisas Espaciais (INPE), Av. dos Astronautas, 1758, São José dos Campos, \\ São Paulo 12227-010, Brazil \\ 2 National Astronomy and Ionosphere Center, Space and Atmospheric Sciences Department, Arecibo Observatory/SRI \\ International, HC3 Box 53995, Arecibo 00612, PR, USA \\ a Now at: Laboratoire de Physique et Chimie de l'Environnement et de l'Espace (LPC2E), CNRS, Orléans 45100, France \\ *Corresponding author: rajkumarhajra@yahoo.co.in \\ 3 Department of Physics, Raja Peary Mohan College, Uttarpara, Hooghly 712258, India \\ 4 Jet Propulsion Laboratory, California Institute of Technology, 4800 Oak Grove Drive Pasadena, California, Pasadena, \\ CA 91109, USA \\ 5 S. K. Mitra Center for Research in Space Environment, University of Calcutta, Calcutta 700009, India
}

Received 30 April 2015 / Accepted 12 June 2016

\section{ABSTRACT}

\begin{abstract}
We present a geomagnetic quiet time (Dst $>-50 \mathrm{nT}$ ) empirical model of ionospheric total electron content (TEC) for the northern equatorial ionization anomaly (EIA) crest over Calcutta, India. The model is based on the 1980-1990 TEC measurements from the geostationary Engineering Test Satellite-2 (ETS-2) at the Haringhata (University of Calcutta, India: 22.58 $8^{\circ}$, $88.38^{\circ}$ E geographic; $12.09^{\circ} \mathrm{N}, 160.46^{\circ}$ E geomagnetic) ionospheric field station using the technique of Faraday rotation of plane polarized VHF $(136.11 \mathrm{MHz})$ signals. The ground station is situated virtually underneath the northern EIA crest. The monthly mean TEC increases linearly with $\mathrm{F}_{10.7}$ solar ionizing flux, with a significantly high correlation coefficient $(r=0.89-0.99)$ between the two. For the same solar flux level, the TEC values are found to be significantly different between the descending and ascending phases of the solar cycle. This ionospheric hysteresis effect depends on the local time as well as on the solar flux level. On an annual scale, TEC exhibits semiannual variations with maximum TEC values occurring during the two equinoxes and minimum at summer solstice. The semiannual variation is strongest during local noon with a summer-to-equinox variability of $\sim 50-100$ TEC units. The diurnal pattern of TEC is characterized by a pre-sunrise (0400-0500 LT) minimum and near-noon (1300-1400 LT) maximum. Equatorial electrodynamics is dominated by the equatorial electrojet which in turn controls the daytime TEC variation and its maximum. We combine these long-term analyses to develop an empirical model of monthly mean TEC. The model is validated using both ETS-2 measurements and recent GNSS measurements. It is found that the present model efficiently estimates the TEC values within a $1-\sigma$ range from the observed mean values.
\end{abstract}

Key words. Ionosphere (equatorial) - Solar activity - Solar cycle - Total electron content - Forecasting

\section{Introduction}

Radio waves traversing the ionosphere experience effects such as group path delay, radio frequency carrier phase advance, Faraday polarization rotation, angular refraction, frequency Doppler shift, scintillation, etc. (e.g., Budden 1961). All of these factors may limit the performance and accuracy of the fail-safe transionospheric communication and navigation link systems. The region around the crest of the equatorial ionization anomaly (EIA) is most vulnerable in this aspect. Most of the above effects exhibited by the signals propagating through the ionosphere are directly proportional, at least to the first order, to the number of free electrons encountered along the path of the signal between the satellite and ground receiver, i.e., the total electron content (TEC) or its time derivative (Ezquer et al. 2004). Modeling of the TEC near the EIA peak is thus important for use in minimizing communication link disruptions.

During the last few decades, great efforts have been made to develop ionospheric models. The majority of the models may be categorized into three groups: (i) empirical models (Bent et al. 1972; Ching \& Chiu 1973; Rawer et al. 1978; Anderson et al. 1987, 1989; Nisbet \& Divany 1987; Tascione et al. 1988; Daniell et al. 1995; Batista et al. 1996; Abdu et al. 2008; Brum et al. 2011, 2012; Bilitza et al. 2012), (ii) theoretical or mathematical models (Bailey et al. 1978; Anderson \& Klobuchar 1983; Anderson et al. 1996; Schunk \& Sojka 1996; Brum et al. 2006), and (iii) parameterized models (Daniell et al. 1995; Souza et al. 2010). The empirical models are based on statistical analyses of long-term ionospheric measurements, while theoretical/mathematical models are developed by solving a set of equations accounting for different physical and chemical processes that take place in the ionosphere. On the other hand, parameterized models are based on theoretical climatology as given by the physics-based model of the ionosphere.

The efficiency of most of the models in reproducing or predicting the ambient ionization or TEC varies largely with geographic locations and geophysical conditions. The region near the EIA or low latitude region has proven to be the most 
difficult of all (McNamara 1983; Anderson et al. 1987; de Paula et al. 1996; Barman et al. 1997; Sibanda \& McKinnell 2009). No currently available ionospheric model can accurately predict the TEC near the anomaly crest or low latitude zone. The region of most concern to the users of satellite-based communication and navigation systems is the region near the anomaly crest. The EIA crest region ionization is mainly controlled by solar ionizing flux and the equatorial fountain effect. However, the variability of solar EUV radiation, equatorial electrodynamics, and the transequatorial wind system introduce extreme variability in the ambient ionization around the crest region. In the present effort, we will analyze the TEC variation using a long (1980-1990) database taken at the ionosphere field station Haringhata (University of Calcutta, India: $22.58^{\circ} \mathrm{N}, 88.38^{\circ} \mathrm{E}$, geographic; $12.09^{\circ} \mathrm{N}$, $160.46^{\circ} \mathrm{E}$ geomagnetic). This station is situated virtually underneath the statistical location of the EIA crest. The analyses are directed toward the development of a local empirical TEC model. We feel that a local model is superior to a global model because the latter may smear out unique features of a particular location. Development of station-specific local models is necessary for application to satellite communication and navigation systems.

\section{Database}

The TEC data (15 min time resolution) are obtained using the technique of Faraday rotation of plane polarized VHF (136.11 MHz) signals from the geostationary Engineering Test Satellite-2 (ETS-2) at Haringhata. The $400 \mathrm{~km}$ subionospheric point of the ETS-2 ray path is located at $21^{\circ} \mathrm{N}$, $92.7^{\circ} \mathrm{E}$ (geographic), $10.27^{\circ} \mathrm{N}, 164.44^{\circ} \mathrm{E}$ (geomagnetic). Detailed descriptions of the ETS-2 mission are given in Fugono et al. (1980). The ETS-2 measurements for the interval between 1980 and 1990 are utilized to develop the TEC empirical model. The model validation was made using ETS-2 observations from 1978 to 1979 . A further validation of the model was performed using recent (2011 and 2012) TEC observations by ground-based Global Navigation Satellite Systems (GNSS) from a nearby station Raja Peary Mohan College (RPMC: $22.65^{\circ} \mathrm{N}, 88.36^{\circ} \mathrm{E}$ geographic; $13.12^{\circ} \mathrm{N}$, $161.68^{\circ}$ E geomagnetic) (Hajra et al. 2012). The GNSS TEC data are recorded at RPMC at $1 \mathrm{~min}$ time resolution using a dual frequency $(1575.42,1227.6 \mathrm{MHz})$ Septentrio PolaRxSPro receiver. We use an elevation mask angle of $50^{\circ}$ for slant-to-vertical conversion of TEC and an azimuth filter of $100^{\circ}-220^{\circ}$ to avoid local time contamination effect. Also, appropriate satellite and receiver bias corrections are incorporated (Sardon et al. 1994; Jakowski et al. 2011). We compare the TEC observation and the present model output with TEC estimated by the International Reference Ionosphere (IRI) model (Bilitza et al. 2012). The IRI model was run online (http://iri.gsfc.nasa.gov/).

We consider $\mathrm{F}_{10.7}$ as the surrogate index for the solar ionizing flux owing to unavailability of a proper EUV database (e.g., Doherty et al. 2000; Mahajan \& Dwivedi 2005). The daily $\mathrm{F}_{10.7}$ data were collected from the website: http:// www.drao.nrc.ca/icarus.

The amplitude of the equatorial electrojet (EEJ) is considered to be the proxy index of the equatorial electric field (see Stolle et al. 2008). The EEJ refers to an enhanced ionospheric current flowing at an altitude of $\sim 100 \mathrm{~km}$ in the narrow latitudinal belt around the magnetic equator, ranging from $5^{\circ} \mathrm{N}$ to $5^{\circ} \mathrm{S}$ (Chapman 1951). It is estimated from the magnetometer horizontal intensity data ( $1 \mathrm{~h}$ time resolution) from Trivandrum $\left(8.29^{\circ} \mathrm{N}, \quad 76.57^{\circ} \mathrm{E}\right.$ geographic; $1.09^{\circ} \mathrm{S}$, $147.84^{\circ} \mathrm{E}$ geomagnetic) and Alibag $\left(18.63^{\circ} \mathrm{N}, 72.87^{\circ} \mathrm{E}\right.$ geographic; $9.52^{\circ} \mathrm{N}, 145.37^{\circ} \mathrm{E}$ geomagnetic) by the method suggested by MacDougall (1969) and Chandra \& Rastogi (1974). Trivandrum is an EEJ station while Alibag is located outside the EEJ belt. Accordingly, the hourly variations of the horizontal component of the geomagnetic field relative to its nighttime values at Alibag are subtracted from the corresponding values at Trivandrum. The magnetometer data are collected from the World Data Centre for Geomagnetism, Mumbai, India (http://wdciig.res.in/WebUI/Home.aspx).

For the present study, we consider only normal EEJ days (eastward during daytime) and geomagnetically quiet conditions (Dst $>-50 \mathrm{nT}$; Gonzalez et al. 1994). Dst data were obtained from the World Data Center for Geomagnetism, Kyoto, Japan (http://wdc.kugi.kyoto-u.ac.jp/).

\section{Model development}

TEC at a specific location is determined by the integrated effects of production, loss, and transport processes (plasma continuity equation). Each of these effects has different weight depending on the geomagnetic/geographic location, solar and geomagnetic activity, season and local time. While production is mainly controlled by solar EUV radiation, transport at the low latitude region is dominated by the equatorial fountain effect (Appleton 1946; Martyn 1955; Duncan 1959; Ross 1966; Das Gupta \& Basu 1973; Richmond et al. 1976; Balan et al. 1993; Doherty et al. 2000). The electron production by photo-ionization of neutral atoms and molecules is proportional to the intensity of solar radiation, governed by the Beer Lambert law. It is also determined by the density and properties of the neutrals (Golton \& Walker 1971; Rastogi \& Sharma 1971; Huang et al. 1989; Klobuchar et al. 1991; Wu et al. 2004). The plasma transport contribution varies with the altitude and is most important above the ionospheric E-layer. In the E-layer where transport is mostly unimportant, electron density is proportional to the square root of the production rate. It may be mentioned that TEC is a height-integrated parameter and is weighted mostly by the electrons in the F-regions, with $\sim 2 / 3$ rd of the contribution coming from regions above the altitude of the F-region peak. The vertical $\mathbf{E} \times \mathbf{B}$ drift of plasma driven by the orthogonal configuration of the geomagnetic field (B) and zonal electric field (E) over the magnetic equator, and subsequent diffusion along the geomagnetic field lines due to gravitational and pressure gradient forces lead to the development of the EIA (Martyn 1955; Duncan 1959). The EIA is a double humped structure in the latitudinal distribution of the ionization at low magnetic latitudes. It is characterized by a region of depleted ionization (ionization trough) at the magnetic equator and two crests of enhanced ionization at around $\pm 15-20^{\circ}$ magnetic latitudes (Appleton 1946). Other than the contributions of production and transport of ionization, the effects of seasons and local times are also important contributors to the variability of TEC. In the present effort, we combine the result of analyses of the solar ionizing flux production, transport of ionized particles, and seasonal and local time variability to develop a model of monthly mean TEC.

The top and middle panels of Figure 1 show the variation of the monthly mean TEC with $\mathrm{F}_{10.7}$ solar flux for the 
1980-1985

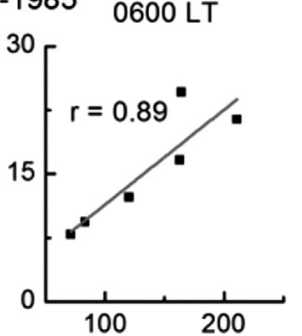

1986-1990

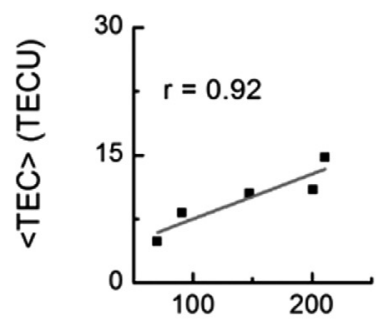

1980-1990

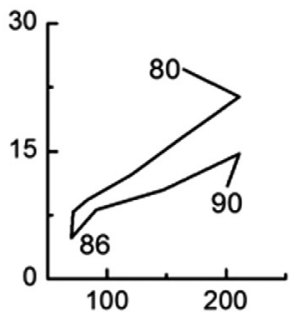

0900 LT
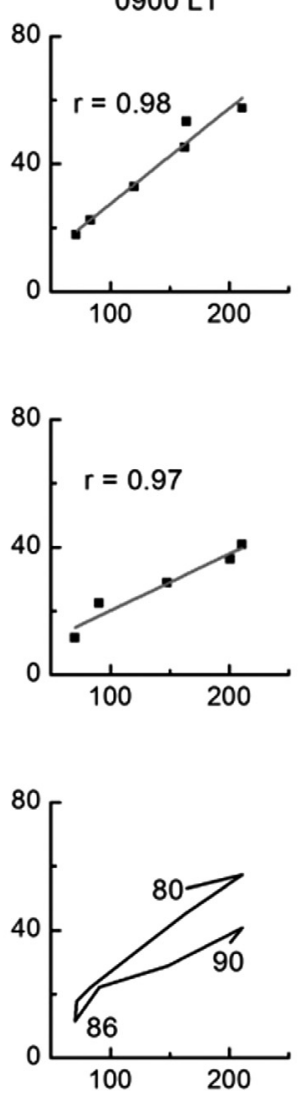

1200 LT
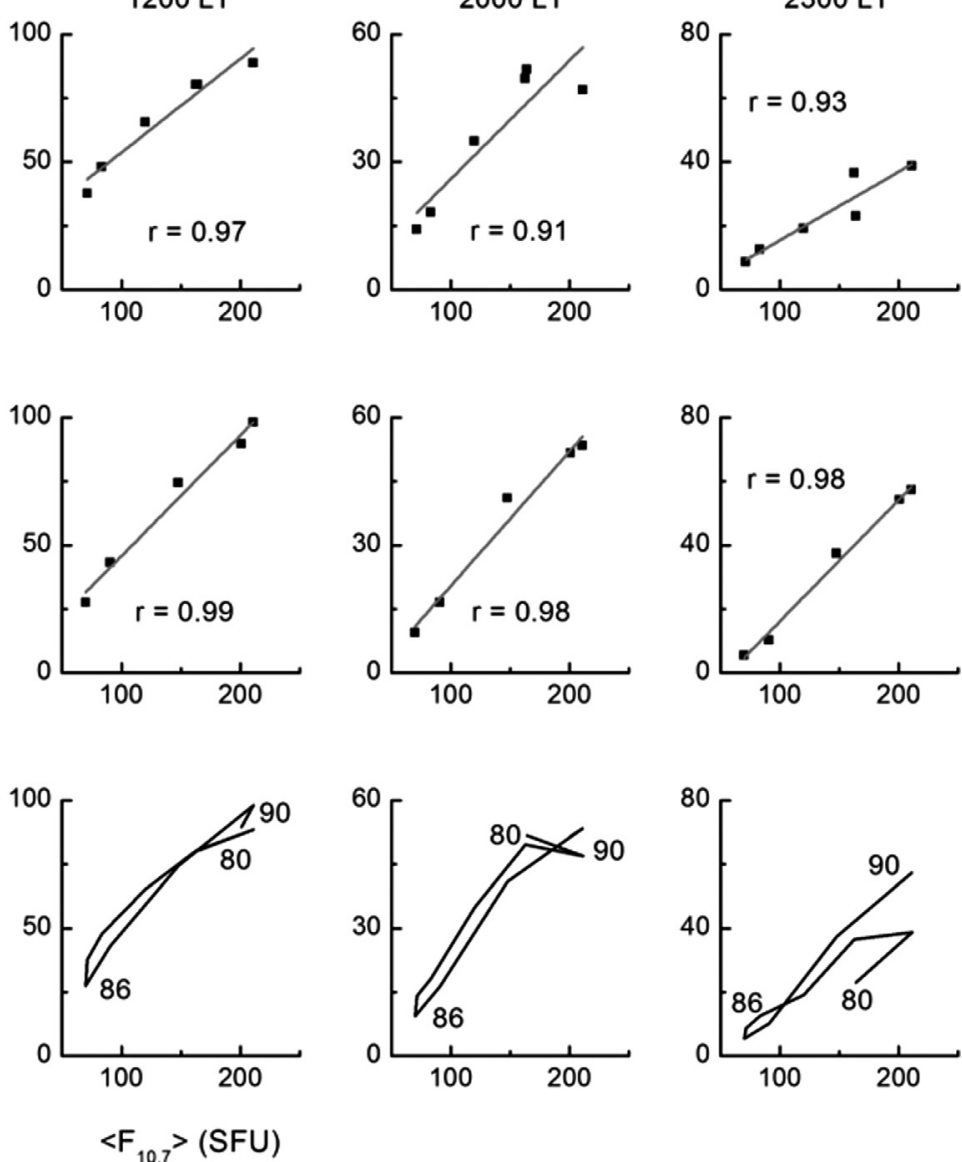

2000 LT
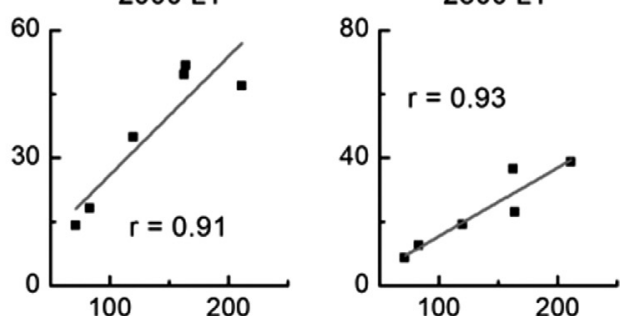
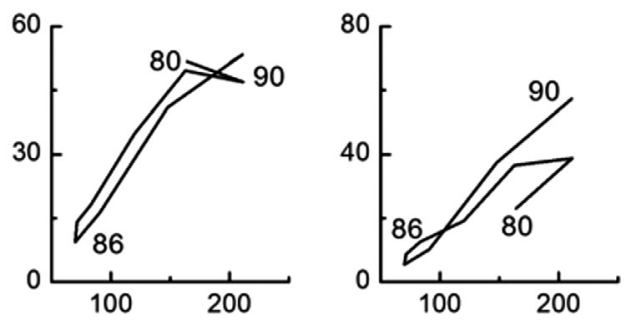

Fig. 1. Variation of monthly mean TEC (TECU) with average $\mathrm{F}_{10.7}$ solar flux (SFU) during August. The top and middle panels show the variations for the descending phase of SC 22 (1980-1985) and the ascending phase of SC 23 (1986-1990), respectively. The linear regression fittings and correlation coefficients $(r)$ between $\langle$ TEC $\rangle$ and $\left\langle\mathrm{F}_{10.7}\right\rangle$ are also shown in each panel. The bottom panel shows the monthly mean TEC variations for both the solar cycle phases together. The corresponding local times are indicated in the top panel. A prominent ionospheric hysteresis effect may be noted in the SC variation of TEC (see text).

descending phase of solar cycle (SC) 21 (1980-1985) and the ascending phase of SC 22 (1986-1990), respectively. As mentioned in Section 2, we only consider normal EEJ days and geomagnetically quiet days with Dst $>-50 \mathrm{nT}$ to estimate the monthly mean TEC values. The month of August was selected for this representation. The results at five different local times (LT $=\mathrm{UT}+0530 \mathrm{~h}): 0600,0900,1200,2000$, and 2300 LT are shown. It can be noted that TEC increases linearly with $\mathrm{F}_{10.7}$ flux increases. The correlation coefficient between TEC and $F_{10.7}$ varies between 0.89 and 0.99 , confirming the dominating solar radiation impact on equatorial TEC during quiet intervals.

In the bottom panel of Figure 1, the monthly mean TEC for 1980-1990 is given. Under similar conditions of solar activity (the same $F_{10.7}$ ), it is found that there are significant differences in the TEC values during the descending and ascending phases of the solar cycle. The TEC in the ascending phase has a different variation from that in the descending epoch. This is called the ionospheric hysteresis effect. The effect is observed in all months and at all local times (not shown to conserve space). The ionospheric hysteresis effect is more prominent in high solar activity intervals than in lower activity ones. It may be noted that this effect has less impact at 1200 LT compared to other time sectors shown in Figure 1. A detailed discussion about the features and causes of the TEC hysteresis effect may be found in Chakraborty \& Hajra (2008) and Hajra (2011). It was shown to exhibit prominent local time effect with temporal flip-over between the ascending and descending phases of the solar cycle. The effect was discussed to be related to varying geomagnetic activity between the ascending and descending phases, interhemispheric plasma flow and neutral wind changes. Peculiar local time dependence of the hysteresis effect deserves further investigation. Due to the aforementioned TEC hysteresis effect, the data for the two epochs are considered separately in the development of our empirical model.

From this analysis, TEC is expressed as a linear function of $\mathrm{F}_{10.7}$ solar flux by Eq. (1):

$$
\operatorname{TEC}_{s\left(\mathrm{~F}_{10.7}, t, m\right)}=a_{s(t, m)} \times \mathrm{F}_{10.7}+c_{s(t, m)} .
$$

Here $\mathrm{TEC}_{s\left(\mathrm{~F}_{10,7}, t, m\right)}$ is expressed in TEC units ( 1 TECU $=10^{16}$ electrons $\mathrm{m}^{-2}$ ). $\mathrm{F}_{10.7}$ is given in solar flux units $\left(1 \mathrm{SFU}=10^{-22} \mathrm{~W} \mathrm{~m}^{-2} \mathrm{~Hz}^{-1}\right) . a_{s(t, m)}$ is the $\mathrm{F}_{10.7}$ dependence rate (the slope, given in TECU SFU ${ }^{-1}$ ) and $c_{s(t, m)}$ predicts $\mathrm{TEC}_{s\left(\mathrm{~F}_{10.7}, t, m\right)}$ for the hypothetical condition of $\mathrm{F}_{10.7}=0 \mathrm{SFU}$ (given in TECU). $t$ and $m$ denote the local time and month number. In the descending and ascending phases of the solar cycle, TEC at each hour of the day is expressed as the 
linear function of $\mathrm{F}_{10.7}$ solar flux for a particular month and the coefficients $\left(a_{s(t, m)}, c_{s(t, m)}\right)$ of linear regression are generated. In each phase, a $24 \times 12$ (number of hours in a day $\times$ number of months in a year) matrix for $a_{s(t, m)}$ is developed as well as another $24 \times 12$ matrix for $c_{s(t, m)}$.

To study the seasonal variation of TEC, we normalize the monthly mean TEC with respect to $\mathrm{F}_{10.7}$ solar flux values. Contour plots of TEC, normalized at $\mathrm{F}_{10.7}=100 \mathrm{SFU}$, for various months at different local times are shown in Figure 2. The normalized TEC exhibits semiannual variations with two peaks around the equinoxes and a minimum during summer solstice. A remarkable local time dependence of the semiannual anomalies is evident in the plots. The semiannual variation is most prominent around local noon (1200-1400 LT) with a summer-to-equinoctial variation of 50-100 TECU. Another important feature is the clear dawn-dusk difference of the TEC values. During dawn, due to low/no solar ionization, low conductivity, and low equatorial electric field (EEJ), weak fountain effect, TEC level at the anomaly crest (present location) is low. On the other hand, presence of pre-reversal enhancement of equatorial electric field and consequent resurgence of equatorial fountain effect seem to play an important role in enhanced dusk time TEC values. The seasonal variations have been suggested to be caused mainly by (i) the seasonal position of the subsolar point in relation to the geomagnetic equator, and (ii) the semiannual variation of neutral composition ([O]/[ $\left[\mathrm{N}_{2}\right]$ ) (Mayr \& Mahajan 1971; Walker et al. 1994; Fuller-Rowell 1998; Rishbeth et al. 2000; Zou et al. 2000).

Using non-linear regression analyses, the seasonal variation is fitted to a sinusoidal curve with a positive residual, and the regression coefficients $\left(a_{m(t)}, c_{m(t)}, \lambda_{m(t)}, \delta_{m(t)}\right)$ are generated at each local time of the day $(t)$ (Eq. (2)):

$$
\mathrm{TEC}_{m(t, m)}=a_{m(t)} \times \sin \left(\frac{2 \pi m}{\lambda_{m(t)}}-\delta_{m(t)}\right)+c_{m(t)} .
$$

Here, the month number $(m)$ is considered to be the variable. Figure 3 shows a sample plot of the curve fitting at three different local times, 1000, 1200, and 0000 LT. Although a similar analysis was performed for all local time sectors with good results, we show these to conserve space. In each phase of the solar cycle, we obtain 24 values (at 24 LTs) for each coefficient. The parameter $\lambda_{m(t)}$, the semiannual periodicity, has the value of $\sim 6$ months.

A further normalization of the solar flux normalized-TEC values on a seasonal basis yields the variation of TEC with local time. The average of the diurnal variation for different months during the descending phase is shown in Figure 4. A few plots are selected to show data from all seasons. Similar results are obtained from other months as well (not shown). The diurnal pattern has a peak around local noon (1200-1400 LT) and minimum before sunrise (0400-0500 LT). This is the typical diurnal variation of TEC around the EIA crest location. This pattern may be described by a sine function of local time (t) with a positive residual value (Eq. (3)):

$$
\mathrm{TEC}_{t(t, m)}=a_{t(m)} \times \sin \left(\frac{2 \pi t}{\lambda_{t(m)}}-\delta_{t(m)}\right)+c_{t(m)} .
$$

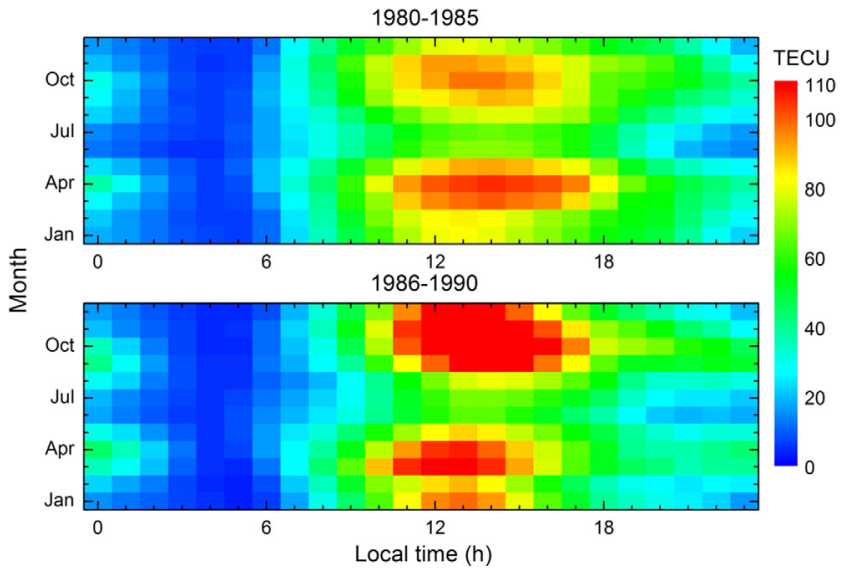

Fig. 2. Contour plots of TEC normalized at $\mathrm{F}_{10.7}=100 \mathrm{SFU}$ for various months at different local times during the descending phase of SC 21 (1980-1985) and the ascending phase of SC 22 (19861990). The values of different colors are given in the legend on the right.

The regression coefficients $\left(a_{t(m)}, c_{t(m)}, \lambda_{t(m)}, \delta_{t(m)}\right)$ are generated for each month $(m)$. This leads to 12 values for each of the coefficients during each phase of the solar cycle. The value of $\lambda_{t(m)}$ is $\sim 24$ hours, which is the span of a diurnal TEC profile.

To study the fountain effect on TEC, as dictated by the EEJ dynamics, the deviations of the monthly mean TEC from the corresponding solar flux normalized values are considered. As the solar flux contributions are observed to be the maximum around 0900 LT (Chakraborty \& Hajra 2008; Hajra 2011), deviations are estimated from solar flux normalized values around this period. TEC deviations are plotted against the EEJ values. An approximate time delay of $\sim 2 \mathrm{~h}$ between the cause (triggering of the equatorial fountain) and the effect (changes in ambient level near the anomaly crest) is incorporated in the selection of EEJ values (Rush \& Richmond 1973; Sethia et al. 1980; Chakraborty \& Hajra 2009). Figure 5 shows sample plots of the TEC variation with EEJ (linear regression fitting) for the months of January, July, and October (Eq. (4)). While similar results are obtained for all months, we select these months from different seasons to conserve space. The correlation coefficient $(0.85)$ between the two is high and statistically significant.

$$
\mathrm{TEC}_{e(\mathrm{EEJ}, t, m)}=a_{e(t, m)} \times\langle\mathrm{EEJ}\rangle+c_{e(t, m)} .
$$

Here, $\langle\mathrm{EEJ}\rangle$ is given in the unit of $\mathrm{nT}$. Through regression analyses, the coefficients $\left(a_{e(t, m)}, c_{e(t, m)}\right)$ are generated for each local time $(t)$ during each month $(m)$ to extract the EEJ contribution to the diurnal variations of TEC. As in the case for the solar flux contribution calculation, we derive separately a $24 \times 12$ matrix for $a_{e(t, m)}$ and a $24 \times 12$ for $c_{e(t, m)}$. This is done separately for the two phases of the solar cycle, as before.

We now perform a multiple-regression analysis (MRA) to express the monthly mean TEC as a combined function of the four sources (solar flux, season, local time, and EEJ), as expressed in Eqs. (1)-(4). MRA is a useful statistical tool that can be used to predict the value of a variable based on the values of two or more other variables (Pearson \& Lee 1908; 
R. Hajra et al.: TEC modeling near the anomaly crest

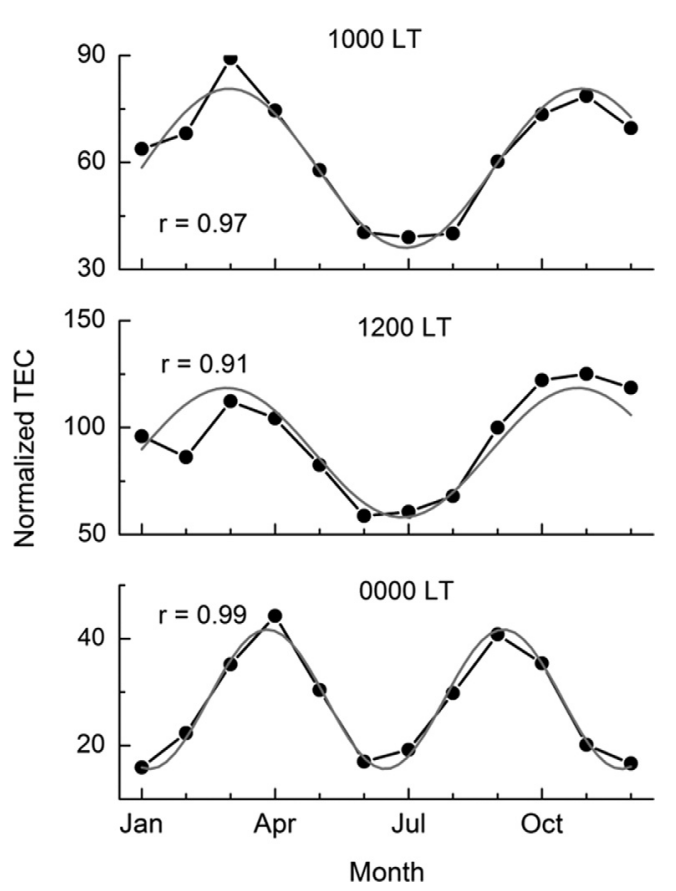

Fig. 3. Seasonal variation of monthly mean TEC (TECU) normalized at $\mathrm{F}_{10.7}=100 \mathrm{SFU}$ during the ascending phase of the SC 22 (1986-1990) at three local times 1000, 1200, and 0000 LT. The filled circles connected by lines show the actual data while the continuous thick curve presents a sinusoidal curve with positive residual fitted to the data. The correlation coefficient $(r)$ is shown in the figure.

Osborne 2000). The final model is formulated below as Eq. (5):

$$
\begin{aligned}
\mathrm{TEC}_{\text {model }\left(\mathrm{F}_{10.7}, t, m, \mathrm{EEJ}\right)}= & \left(a_{s(t, m)} \times \mathrm{F}_{10.7}+c_{s(t, m)}\right) \\
& +\left(a_{m(t)} \times \sin \left(\frac{2 \pi m}{\lambda_{m(t)}}-\delta_{m(t)}\right)+c_{m(t)}\right) \\
& +\left(a_{t(m)} \times \sin \left(\frac{2 \pi t}{\lambda_{t(m)}}-\delta_{t(m)}\right)+c_{t(m)}\right) \\
& +\left(a_{e(t, m)} \times\langle\mathrm{EEJ}\rangle+c_{e(t, m)}\right) .
\end{aligned}
$$

The four sets of regression coefficients generated through MRA are adjusted with those obtained previously to generate the final set of coefficients $\left(a_{s(t, m)}, a_{m(t)}, a_{t(m)}, a_{e(t, m)}, c_{s(t, m)}\right.$, $\left.c_{m(t)}, c_{t(m)}, c_{e(t, m)}\right)$. Finally a database containing two $24 \times 12$ (LT $\times$ month) matrices for each of the coefficients $a_{s(t, m)}$, $a_{e(t, m)}, c_{s(t, m)}, c_{e(t, m)}$, two $24 \times 1$ (LT) matrices for $a_{m(t)}, c_{m(t)}$, $\lambda_{m(t)}$, and $\delta_{m(t)}$, and two $12 \times 1$ (month) matrices for $a_{t(m)}$, $c_{t(m)}, \lambda_{t(m)}$, and $\delta_{t(m)}$ is generated. The $\mathrm{F}_{10.7}$ solar flux, month number $(m)$, local time $(t)$, and monthly mean EEJ $(\langle$ EEJ $\rangle)$ are the four input parameters used to get the monthly mean TEC $\left(\mathrm{TEC}_{\text {model }\left(\mathrm{F}_{10.7}, t, m, \mathrm{EEJ}\right)}\right)$ as the output using the empirical model.

\section{Model comparison and validation}

Using the above-derived empirical model, the diurnal values of monthly mean TEC are calculated for the period from 1980 to 1990. Figure 6 shows a comparison of the TEC values
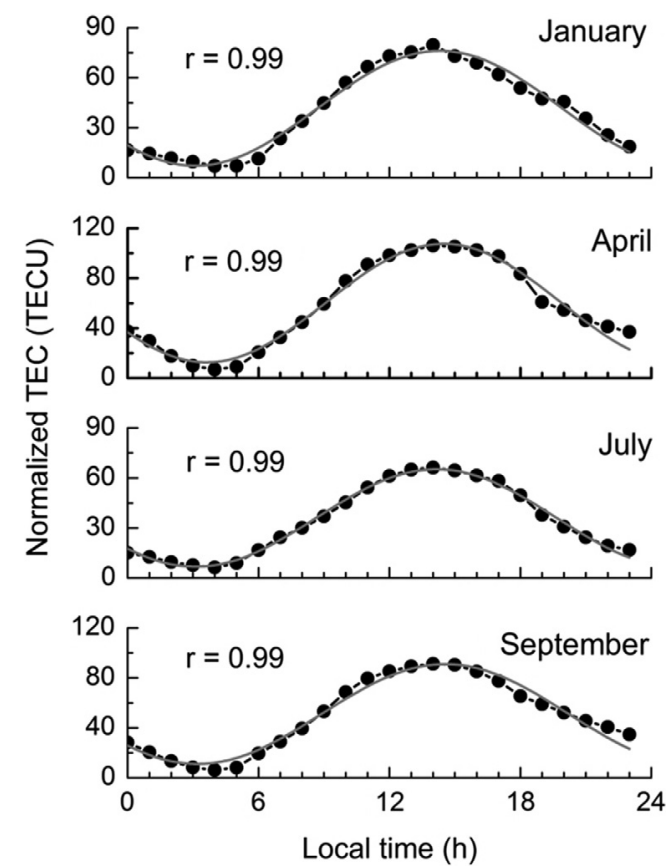

Fig. 4. Diurnal variation of normalized TEC (TECU) for different months in the descending phase of the SC 21 (1980-1985). The filled circles connected by lines show the actual data while the continuous thick curve presents a sinusoidal curve with positive residual fitted to the data. The respective correlation coefficient $(r)$ is also shown in the figure.

estimated using the empirical model (TEC model) with the observed values (TEC observed) at different hours of the day during various months of the ascending phase of SC 22 (1986-1990). The identical nature of the two contour plots confirms that the model fits well with the observed TEC during different solar activity conditions. This is as expected because the dataset is the one used for development of the model. This constitutes a verification of the code, which is a standard technical requirement for every empirical model.

A further validation of our empirical model is made using TEC observations for the years 1978 and 1979. We remind the reader that the model was developed using database of TEC during a different time period (1980-1990). Figure 7 shows some sample plots for the comparison of the TEC values estimated by the empirical model with the observed TEC values during different months of 1978 and 1979. In the same figure, the TEC estimations from the IRI model are also shown for comparison. The continuous curves show the monthly mean TEC values while the vertical bars represent the standard $(1-\sigma)$ deviations of the observed TEC. The TEC values estimated by the present model are within the $1-\sigma$ range of the observed monthly mean values during both day and night local times. On the other hand, the IRI model seems not to be accurate enough to predict/estimate TEC within the $1-\sigma$ range of the actual observation. Large deviations between the model and the data are noted from local afternoon to morning time sector.

It is interesting to see if the model works for independent observations (other than ETS-2 measurements). In Figure 8 the thin blue lines show the variation of daily vertical TEC from GNSS satellites with elevation angle $>50^{\circ}$ and azimuth of $100^{\circ}-220^{\circ}$ during April 2011, June 2012, and December 2012. The data covers three seasons: equinox, local summer, and winter, respectively. The IRI model outputs are not shown 


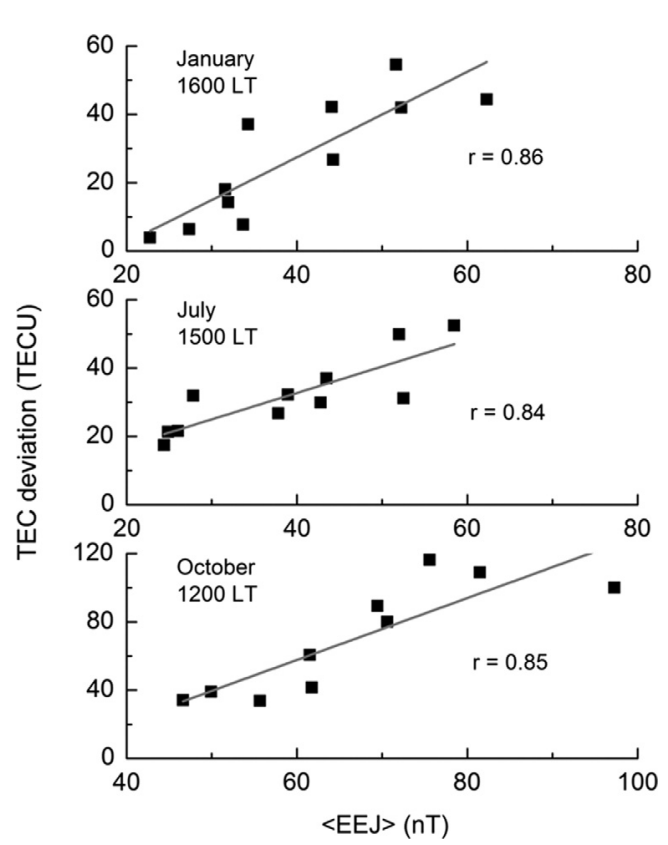

Fig. 5. Deviations of monthly mean TEC (TECU) at the mentioned local times vs. monthly mean EEJ strength (nT) at $2 \mathrm{~h}$ earlier time for the months of January, July, and October for the entire period of observation (1980-1990). The linear regression fitting and correlation coefficient $(r)$ between the two are also shown.

as it is evident from Figure 7 that IRI is not accurate enough for the present observing station. Large day-to-day variations can be seen in the plots. The bold blue lines with filled squares give the monthly mean variation along with $1-\sigma$ standard deviations. The bold red lines show the model estimations of monthly mean TEC. The model evidently is able to estimate the average variation during different seasons as observed by the GNSS satellites. This further establishes the efficiency of the present model.

It may be mentioned that there are significant differences in the variations and absolute values of peaks/deeps among the solar cycles, as depicted by $\mathrm{F}_{10.7}$ solar flux variation. The present model was developed using database of TEC from 1980 to 1990 , the period including the descending phase of SC 21 and the ascending phase of SC 22. The model has specific fitting parameters for each month of the year for each part of the solar cycle. Comparing this model with data from the ascending phase close to the peak of SC 21 (1978 and 1979, Fig. 7) and that from few months of data in the ascending phase of SC 24 (2011 and 2012, Fig. 8) may not be sufficient. However, it is expected to be valid for other solar cycles as well because the model uses monthly mean $\mathrm{F}_{10.7}$ solar fluxes and EEJ from the corresponding solar cycles as input parameters. Unfortunately, this cannot be verified at present owing to the unavailability of TEC data from ETS-2 or a suitably large database from other observations for a different solar cycle.

\section{Discussion and conclusions}

As discussed in Section 1, understanding of TEC variability is important for the maintenance of fail-safe transionospheric communication and navigation links. The largest TEC values

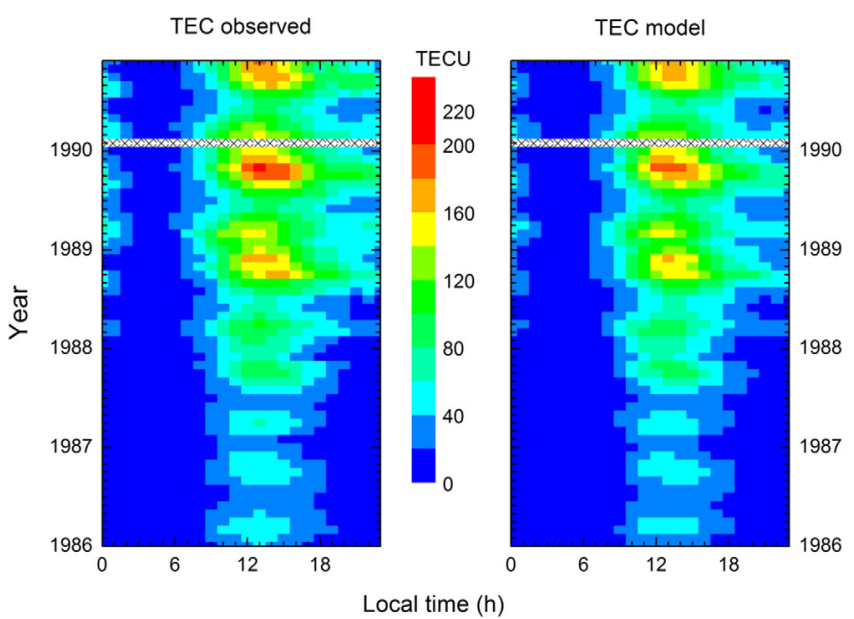

Fig. 6. Contour plots of TEC values observed experimentally (TEC observed) and estimated by the empirical model (TEC model) at different hours of the day during various months of the ascending phase of the SC 22 (1986-1990). The values of different colors are given in the legend in the middle. The crosses represent data gaps during February of 1990.

with the highest variability are observed near the EIA crest region, thus this region is of paramount importance. There have been several previous attempts, mentioned earlier, to model the ambient ionosphere. It has been noted that past studies revealed that global models such as IRI, PIM, SLIM, and SUPIM in general do not accurately represent TEC variations near the anomaly crest regions (see Barman et al. 1997; Ezquer et al. 2004; Abdu et al. 2008). This necessitates the development of station-specific regional models of ionospheric parameters (Klobuchar \& Allen 1970; Baruah et al. 1993; Gulyaeva 1999; Venkata Ratnam \& Sarma 2006; Rao 2007). It may be mentioned that until now no appropriate regional model of TEC for the northern crest of EIA in the Indian longitude zone has successfully been developed. This paper is our attempt at a creation of a practical and useable model for the Indian longitude sector.

The present TEC model development was based on statistical analyses on a long-term (1980-1990) database of TEC from Calcutta situated near the northern crest of the EIA in the Indian zone (Chakraborty \& Hajra 2008, 2009; Hajra 2011). The diurnal TEC dependences on solar ionizing flux $\left(F_{10.7}\right)$, equatorial electrodynamics $(\mathrm{EEJ})$, season, and local time were analyzed to develop the model using linear, non-linear, and multiple-regression analyses. The model reproduces the observed TEC values well within the $1-\sigma$ range of the observed monthly mean for the entire data period. Further validations of the model were made using observed ETS-2 TEC data for the years 1978 and 1979, and GNSS TEC measurements for 2011 and 2012.

A monthly mean model such as the present one may provide useful information about the degree of disturbance in the region, by comparing real-time data to the average pattern. Such disturbance levels could be useful in forecasting. Development of the ionospheric (and thermospheric) forecasting model for the solar wind disturbances is one of the most important aspects of the modern space weather studies (Mannucci et al. 2015 and references therein). For example, a few days before a coronal mass ejection or a high-speed solar wind stream arrival is predicted to occur at Earth 


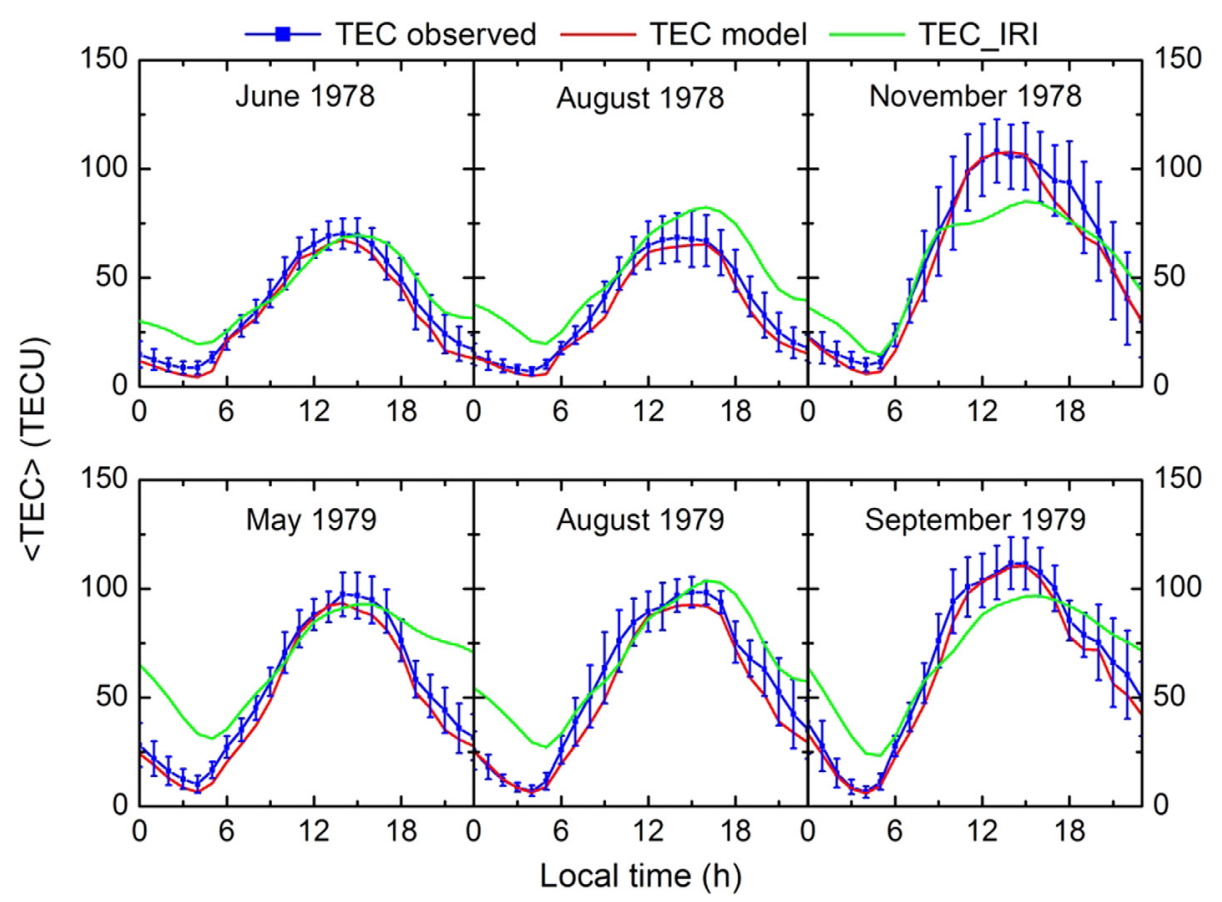

Fig. 7. Diurnal variations of monthly mean observed TEC (TEC observed), estimated TEC using the present empirical model (TEC model), and the IRI model output (TEC_IRI), all in TECU, for several months of the years 1978 and 1979. The vertical bars show the standard (1 $-\sigma$ ) deviations of the observed TEC.

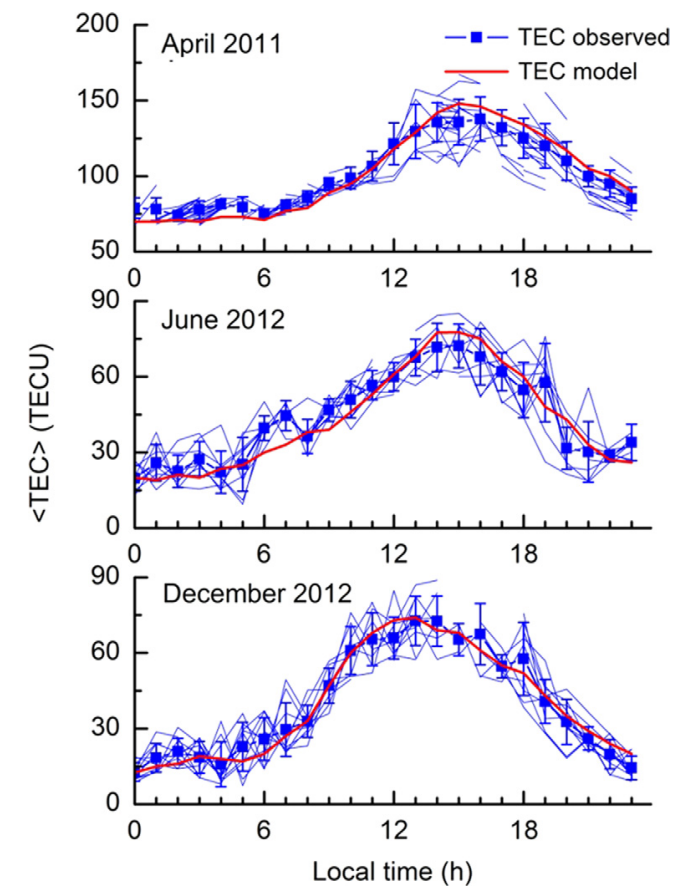

Fig. 8. Diurnal variation of GNSS TEC and estimated TEC using the present empirical model for April 2011, June 2012, and December 2012. The blue thin lines show diurnal TEC during different days and the bold lines connected by filled squares show the monthly mean TEC observed by GNSS. The vertical bars show the standard $(1-\sigma)$ deviations of the observed monthly mean TEC. The red solid lines show the model estimation of monthly mean TEC.

(Norquist 2013; Tobiska et al. 2013). Knowing whether the ionosphere is near or away from the average condition (present model) could be useful for the forecasting.

\section{Final comments}

Below the F2-layer peak, i.e., at the Chapman layers where plasma transport is generally not important, the plasma density largely depends on the cosine of the solar zenith angle (SZA), according to the theory of photo-ionization (Chapman 1931). The present model does not explicitly account for the SZA and its variation through a Chapman function. However, the local time and seasonal dependences of TEC are expressed as sinusoidal functions of local time and month, respectively. These may be associated with SZA dependence. TEC is shown to exhibit hysteresis effect between the descending and ascending phases of the solar cycle, with prominent local time dependence. This might be associated with a difference between the SZAs. More research is required for any conclusions on this. As mentioned in Section 3, the plasma density profile depends on a long and complex chain of processes in terms of production, loss, and transport of the plasma. In the present regression model development which is solely empirical, this chain of processes is not visible. This may lead to the observed errors in the model.

Acknowledgements. The work of R.H. is financially supported by Fundação de Amparo à Pesquisa do Estado de São Paulo (FAPESP) through post-doctoral research fellowship at INPE. The work of S.K.C. is supported by DST SERB Project, Govt. of India. E.E. would like to thank the Brazilian CNPq (302583/2015-7) agency for financial support. Portions of this research were performed at the Jet Propulsion Laboratory, California Institute of Technology under contract with NASA. The Arecibo Observatory is operated by SRI International in collaboration with the Universities Space Research Association (USRA) and the Universidad Metropolitana (UMET) under a cooperative agreement with the National Science Foundation (NSF), Award Number 1160876. We would like to thank the referees and the editors for valuable suggestions leading to substantial improvement of the manuscript. The editor thanks three anonymous referees for their assistance in evaluating this paper. 


\section{References}

Abdu, M.A., C.G.M. Brum, I.S. Batista, J.H.A. Sobral, E.R. de Paula, and J.R. Souza. Solar flux effects on equatorial ionization anomaly and total electron content over Brazil: observational results versus IRI representations. Adv. Space Res., 42, 617-625, 2008, DOI: 10.1016/j.asr.2007.09.043.

Anderson, D.N., and J.A. Klobuchar. Modeling the total electron content observations above Ascension Island. J. Geophys. Res., 88, 8020-8024, 1983.

Anderson, D.N., M. Mendillo, and B. Herniter. A semi-empirical low-latitude ionospheric model. Radio Sci., 22, 292-306, 1987.

Anderson, D.N., J.M. Forbes, and M. Codrescu. A fully analytic, low- and middle-latitude ionospheric model. J. Geophys. Res., 94, 1520-1524, 1989.

Anderson, D.N., D.T. Decker, and C.E. Valladares. Global theoretical ionospheric model (GTIM) in Solar-Terrestrial Energy Program: Handbook of Ionospheric Models, Natl. Oceanic and Atmos. Admin, Boulder, CO, 133-152, 1996.

Appleton, E.V. Two anomalies in the ionosphere. Nature, 157, 691-693, 1946.

Bailey, G.J., R.J. Moffett, and J.A. Murphy. Interhemispheric flow of thermal plasma in a closed magnetic flux tube at mid-latitudes under sunspot minimum conditions. Planet. Space Sci., 26, 753-765, 1978.

Balan, N., G.J. Bailey, and B. Jayachandran. Ionospheric evidence for a nonlinear relationship between the solar EUV and 10.7-cm fluxes during an intense solar cycle. Planet. Space Sci., 41, 141-145, 1993.

Barman, M.K., A.K. Barbara, and M. Devi. Measured and computed ionospheric electron content in the equatorial anomaly crest region. J. Atmos. Sol. Terr. Phys., 59, 2069-2075, 1997.

Baruah, S., P.K. Bhuyan, and T.R. Tyagi. Modeling of ionospheric electron content over Lunping-an empirical approach. Indian J. Radio Space Phys., 22, 325-330, 1993.

Batista, I.S., R.T. De Medeiros, M.A. Abdu, J.R. De Sousa, G.J. Bailey, and E.R. De Paula. Equatorial ionosphere vertical plasma drift model over the Brazilian region. J. Geophys. Res., 101, 10887-10892, 1996.

Bent, R.B., S.K. Llewellyn, and M.K. Walloch. Description and evaluation of the Bent ionospheric model, DBA Systems, Inc, Melbourne, Florida, F04701-72-C-0380, Space \& Missile Systems Organization, Los Angeles, California, 1972.

Bilitza, D., S.A. Brown, M.Y. Wang, J.R. Souza, and P.A. Roddy. Measurements and IRI model predictions during the recent solar minimum. J. Atmos. Sol. Terr. Phys., 86, 99-106, 2012, DOI: $10.1016 /$ j.jastp.2012.06.010.

Brum, C.G.M., F.S. Rodrigues, P.T. dos Santos, A.C. Matta, N. Aponte, S.A. Gonzalez, and E. Robles. A modeling study of foF 2 and hmF2 parameters measured by the Arecibo incoherent scatter radar and comparison with IRI model predictions for solar cycles 21, 22, and 23. J. Geophys. Res., 116, A03324, 2011, DOI: $10.1029 / 2010 J A 015727$.

Brum, C.G.M., M.A. Abdu, I.S. Batista, A.J. Carrasco, and P.M. Terra. Numerical simulation of nighttime electron precipitation in the lower ionosphere over a sub-auroral region. Adv. Space Res., 37, 1051-1057, 2006, DOI: 10.1016/j.asr.2006.02.003.

Brum, C.G.M., C.A. Tepley, J.T. Fentzke, E. Robles, P.T. dos Santos, and S.A. Gonzalez. Long-term changes in the thermospheric neutral winds over Arecibo: climatology based on over three decades of Fabry-Perot observations. J. Geophys. Res., 117, A00H14, 2012, DOI: 10.1029/2011JA016458.

Budden, K.G. Radio waves in the ionosphere: the mathematical theory of the reflection of radio waves from stratified ionized layers, Cambridge University Press, Cambridge, England, 1961.

Chakraborty, S.K., and R. Hajra. Solar control of ambient ionization of the ionosphere near the crest of the equatorial anomaly in the Indian zone. Ann. Geophys., 26, 47-57, 2008.

Chakraborty, S.K., and R. Hajra. Electrojet control of ambient ionization near the crest of the equatorial anomaly in the Indian zone. Ann. Geophys., 27, 93-105, 2009.
Chandra, H., and R.G. Rastogi. Geomagnetic storm effects on ionospheric drifts and equatorial Es over the magnetic equator. Ind. J. Radio Space Phys., 3, 332-336, 1974.

Chapman, S. The absorption and dissociative or ionizing effect of monochromatic radiation of an atmosphere on a rotating Earth. Proc. Phys. Soc., 43, 26-45, 1931.

Chapman, S. The equatorial electrojet as detected from the abnormal electric current distribution above Huancayo, Peru and elsewhere. Arch. Meteorol. Gephys. Bioclimatal, A4, 368-390, 1951.

Ching, B.K., and Y.T. Chiu. A phenomenological model of global ionospheric electron density in the E, F1 and F2 region. J. Atmos. Terr. Phys., 35, 1615-1630, 1973.

Daniell, R.E., L.D. Brown, D.N. Anderson, M.W. Fox, P.H. Doherty, D.T. Decker, J.J. Sojka, and R.W. Schunk. Parameterized ionospheric model: a global ionospheric parameterization based on first principles models. Radio Sci., 30, 1499-1510, 1995.

Das Gupta, A., and S. Basu. Investigations on ionospheric electron content in the equatorial region as obtained by orbiting beacon satellite. Ann. Geophys., 29, 409-419, 1973.

de Paula, E.R., J.R. de Souza, M.A. Abdu, G.J. Bailey, I.S. Batista, J.A. Bittencourt, and E. Bonelli. Ionospheric electron content over Brazilian low latitude and its comparison with the IRI and SUPIM models. Adv. Space Res., 18, 245-248, 1996.

Doherty, P.H., J.A. Klobuchar, and J.M. Kunches. Eye on the ionosphere: the correlation between solar $10.7 \mathrm{~cm}$ radio flux and ionospheric range delay. GPS Sol., 3, 75-79, 2000.

Duncan, R.A. The equatorial F-region of the ionosphere. J. Atmos. Terr. Phys., 18, 89-100, 1959.

Ezquer, R.G., C. Brunini, M. Mosert, A. Meza, R. del V. Oviedo, E. Kiorcheff, and S.M. Radicella. GPS-VTEC measurements and IRI predictions in the South American sector. Adv. Space Res., 34, 2035-2043, 2004.

Fugono, N., R. Hayashi, and Y. Ishizawa. ETS-II experiments part I: Japan's first geostationary satellite. IEEE Trans. Aerosp. Electron. Syst., 16, 549-557,1980, DOI: 10.1109/TAES.1980.308921.

Fuller-Rowell, T.J. The "thermospheric spoon": a mechanism for the semiannual density variation. J. Geophys. Res., 103, 3951-3956, 1998.

Golton, E., and G.O. Walker. Observations of ionospheric electron content across the equatorial anomaly at sunspot minimum. J. Atmos. Terr. Phys., 33, 1-11, 1971.

Gonzalez, W.D., J.A. Joselyn, Y. Kamide, H.W. Kroehl, G. Rostoker, B.T. Tsurutani, and V. Vasyliunas. What is a geomagnetic storm? J. Geophys. Res., 99, 5771-5792, 1994.

Gulyaeva, T.L. Regional analytic model of ionospheric total electron content: monthly mean and standard deviation. Radio Sci., 34, 1507-1512, 1999.

Hajra, R. A study on the variability of total electron content near the crest of the equatorial anomaly in the Indian zone. Ph.D. thesis, University of Calcutta, 2011.

Hajra, R., S.K. Chakraborty, S. Mazumdar, and S. Alex. Evolution of equatorial irregularities under varying electrodynamical conditions: a multitechnique case study from Indian longitude zone. J. Geophys. Res., 117, A08331, 2012, DOI: $10.1029 / 2012 J A 017808$.

Huang, Y.N., K. Cheng, and S.W. Chen. On the equatorial anomaly of the ionospheric total electron content near the northern anomaly crest. J. Geophys. Res., 94, 13515-13525, 1989.

Jakowski, N., C. Mayer, M.M. Hoque, and V. Wilken. Total electron content models and their use in ionosphere monitoring. Radio Sci., 46, RS0D18, 2011, DOI: 10.1029/2010RS004620.

Klobuchar, J.A., and R.S. Allen. A first-order prediction model of total electron content group path delay for a midlatitude ionosphere. Air Force Surveys in Geophysics, 222, AFCRL-700403, 1970.

Klobuchar, J.A., D.N. Anderson, and P.H. Doherty. Model studies of the latitudinal extent of the equatorial anomaly during equinoctial conditions. Radio Sci., 26, 1025-1047, 1991. 
R. Hajra et al.: TEC modeling near the anomaly crest

MacDougall, J.W. The equatorial ionospheric anomaly and the equatorial electrojet. Radio Sci., 4, 805-810, 1969.

Mahajan, K.K., and A.K. Dwivedi. Solar EUV flux during sunspot cycles 21,22 and 23 - correlation with proxy indices and real time prediction. Indian J. Radio Space Phys., 34, 153-160, 2005.

Mannucci, A.J., O.P. Verkhoglyadova, B.T. Tsurutani, X. Meng, $\mathrm{X}$. Pi, et al. Medium-range thermosphere-ionosphere storm forecasts. Space Weather, 13, 125-129, 2015, DOI: $10.1002 / 2014$ SW001125

Martyn, D.F. Geomagnetic anomalies of the F2 region and their interpretation. In: The Physics of the Ionosphere, Phys. Soc., London, 260-264, 1955.

Mayr, H.G., and K.K. Mahajan. Seasonal variation in the F2 region. J. Geophys. Res., 76, 1017-1027, 1971.

McNamara, L.F. Prediction of total electron content using the International Reference Ionosphere in Environmental Research Papers. 853, AFGL-TR-83-0239, 1983.

Nisbet, J.S., and R. Divany. Instructions for running the PC version of the Penn State Mark III ionospheric model. Sci. Rep. CSSL SCI 484, Penn. State Univ., University Park, PA,1987.

Norquist, D.C. Forecast performance assessment of a kinematic and a magnetohydrodynamic solar wind model. Space Weather, 11, 17-33, 2013, DOI: 10.1029/2012SW000853.

Osborne, J.W. Prediction in multiple regression. Prac. Assess. Res. Eval., 7, 2000, http://pareonline.net/getvn.asp?v=7\&n=2.

Pearson, K., and A. Lee. On the generalized probable error in multiple normal correlation. Biometrika, 6, 59-68, 1908.

Rao, K.N.S. GAGAN-the Indian satellite based augmentation system. Indian J. Radio Space Phys., 36, 293-302, 2007.

Rastogi, R.G., and R.P. Sharma. Ionospheric electron content at Ahmedabad (near the crest of equatorial anomaly) by using beacon satellites transmissions during half a solar cycle. Planet. Space Sci., 19, 1505-1517, 1971.

Rawer, K., D. Bilitza, and S. Ramakrishnan. Goals and status of the International Reference Ionosphere. Rev. Geophys. Space Phys., 16, 177-181, 1978.

Richmond, A.D., S. Matsushita, and J.D. Tarpley. On the production mechanism of electric currents and fields in the ionosphere. J. Geophys. Res., 81, 547-555, 1976.

Rishbeth, H., I.C.F. Muller-Wodarg, L. Zou, T.J. Fuller-Rowell, G.H. Millward, R.J. Moffett, D.W. Idenden, and A.D. Aylward. Annual and semiannual variations in the ionospheric F2-layer: II. Physical discussion. Ann. Geophys., 18, 945-956, 2000.

Ross, W.J. Measurement of electron content at the magnetic equator. J. Geophys. Res., 71, 3671-3676, 1966.

Rush, C.M., and A.D. Richmond. The relationship between the structure of the equatorial anomaly and the strength of the equatorial electrojet. J. Atmos. Terr. Phys., 35, 1171-1180, 1973.
Sardon, E., A. Rius, and N. Zarraoa. Estimation of the receiver differential biases and ionospheric total electron content from Global Positioning System observations. Radio Sci., 29, 577-586, 1994, DOI: 10.1029/94RS00449.

Schunk, R.W., and J.J. Sojka. Ionospheric models. In: H., Kohl, R. Ruster, and K. Schletel, Editors. Modern Ionospheric Science, Eur. Geophys. Soc, Katlenburg-Lindau, Germany, 181-215, 1996.

Sethia, G., R.G. Rastogi, M.R. Deshpande, and H. Chandra. Equatorial electrojet control of the low latitude ionosphere. J. Geomag. Geoelectr., 32, 207-216, 1980.

Sibanda, P., and L.A. McKinnell. The applicability of existing topside ionospheric models to the South African region. S. Afr. J. Sci., 105, 387-390, 2009.

Souza, J.R., C.G.M. Brum, M.A. Abdu, I.S. Batista, W.D. Asevedo Jr., G.J. Bailey, and J.A. Bittencourt. Parameterized Regional Ionospheric Model and a comparison of its results with experimental data and IRI representations. Adv. Space Res., 46, 1032-1038, 2010.

Stolle, C., C. Manoj, H. Luhr, S. Maus, and P. Alken. Estimating the daytime equatorial ionization anomaly strength from electric field proxies. J. Geophys. Res., 113, A09310, 2008, DOI: 10.1029/2007JA012781.

Tascione, T.F., H.W. Kroehl, R. Creiger, J.W. Freeman Jr., R.A. Wolf, R.W. Spiro, R.V. Hilmer, J.W. Shade, and B.A. Hausman. New ionospheric and magnetospheric specification models. Radio Sci., 23, 211-222, 1988.

Tobiska, W.K., D. Knipp, W.J. Burke, D. Bouwer, J. Bailey, D. Odstrcil, M.P. Hagan, J. Gannon, and B.R. Bowman. The Anemomilos prediction methodology for Dst. Space Weather, 11, 490-508, 2013, DOI: 10.1002/swe.20094.

Venkata Ratnam, D., and A.D. Sarma. Modeling of Indian ionosphere using MMSE estimator for GAGAN applications. J. Ind. Geophys. Uni., 10, 303-312, 2006.

Walker, G.O., J.H.K. Ma, and E. Golton. The equatorial ionospheric anomaly in electron content from solar minimum to solar maximum for South East Asia. Ann. Geophys., 12, 195-209, 1994.

Wu, C.C., C.D. Fry, J.Y. Liu, K. Liou, and C.L. Tseng. Annual TEC variation in the equatorial anomaly region during the solar minimum: September 1996-August 1997. J. Atmos. Sol. Terr. Phys., 66, 199-207, 2004.

Zou, L., H. Rishbeth, I.C.F. Muller-Wodarg, A.D. Aylward, G.H. Millward, T.J. Fuller-Rowell, D.W. Idenden, and R.J. Moffett. Annual and semiannual variations in the ionospheric F2-layer. I. Modeling. Ann. Geophys., 18, 927-944, 2000.

Cite this article as: Hajra R, Chakraborty S.K, Tsurutani B.T, DasGupta A, Echer E, et al. An empirical model of ionospheric total electron content (TEC) near the crest of the equatorial ionization anomaly (EIA). J. Space Weather Space Clim., 6, A29, 2016, DOI: 10.1051/swsc/ 2016023. 